\title{
Pengembangan Permainan Ludo Kimia Sebagai Media Pembelajaran Pada Materi Bentuk Molekul Kelas X SMA/MA
}

\author{
N S Yolanda ${ }^{1}$ and Iswendi ${ }^{1^{*}}$ \\ ${ }^{1}$ Pendidikan Kimia, Universitas Negeri Padang, Jl. Prof. Dr. Hamka Air Tawar Barat, \\ Padang Utara, Sumatera Barat 25171, Indonesia \\ *iswendi@fmipa.unp.ac.id
}

\begin{abstract}
Chemistry Ludo is one of the game based learning media as a variety of students' exercises to stabilize their concepts in Molecular Geometry material. The purpose of this study is to produce Chemistry Ludo as a learning medium for Molecular Geometry material and to determine its validity and practicality level based on media functions and characteristics of practical media. The type of this research is Research and Development (R\&D) using 4-D (Four D) models, namely (1) define, (2) design, (3) develop, and (4) disseminate. This learning medium was validated by two lecturers majoring in Chemistry at FMIPA UNP and two Chemistry teachers at SMAN 2 Pariaman. Determining the level of practicality was obtained from two Chemistry teachers and 34 students of XI IPA 2 class at SMAN 2 Pariaman. The instruments used in this research were the validation and practicality questionnaires. The technique of data collection was questionnaires. In analyzing the data, the researcher used Cohen Kappa moment formula. The results of analysis showed that Chemistry Ludo as a learning media in the Molecular Geometry material has a validity level of 0.82 with a Very High category and the practical values of teachers and students are 0.96 and 0.86 with a very high category. This data showed that the development of Chemistry Ludo can be used as a learning medium in Molecular Geometry material.
\end{abstract}

\section{Pendahuluan}

Materi bentuk molekul pada Kurikulum 2013 merupakan salah satu materi yang dipelajari oleh siswa kelas X SMA/MA semester pertama. Materi bentuk molekul berisi pengetahuan faktual, pengetahuan konseptual, dan pengetahuan prosedural. Berdasarkan karakteristik materi tersebut diperlukan pengetahuan tentang materi bentuk molekul, banyak membaca, berdiskusi, dan mengerjakan latihan agar tercapainya Indikator Pencapaian Kompetensi (IPK) sesuai dengan kurikulum 2013.

Berdasarkan hasil wawancara terhadap guru kimia di SMAN 1 Sawahlunto dan SMAN 2 Pariaman, menunjukan bahwa materi bentuk molekul diajarkan menggunakan modul, buku teks, Lembar Kerja Siswa (LKS), powerpoint, dan gambar. Latihan yang diberikan guru bersumber dari modul, buku teks, dan LKS. Dapat disimpulkan guru belum pernah menggunakan permainan sebagai variasi latihan pada materi ini. Ditinjau dari karakteristik siswa dan hasil angket yang telah diberikan kepada siswa kelas $\mathrm{X}$ di SMAN 1 Sawahlunto dan SMAN 2 Pariaman diperoleh informasi bahwa aktifitas siswa dalam mengerjakan latihan masih rendah, bersifat individual, kurang berdiskusi, dan kurang kompetitif. Hal ini dikarenakan soal yang diberikan belum sesuai dengan karakteristik siswa yang suka berkelompok, senang berdiskusi, dan menyukai permainan [1]. Oleh karena itu, dibutuhkan suatu media pembelajaran yang dapat menarik perhatian siswa dalam memahami materi tersebut, sehingga dapat memantapkan konsep siswa. Salah satunya adalah penggunaan media pembelajaran berupa permainan.

Permainan dapat melibatkan siswa dalam pembelajaran aktif, memunculkan rasa gembira, dan menambah motivasi siswa [2]. Media pembelajaran berupa permainan yang dapat digunakan pada materi bentuk molekul salah satunya adalah Ludo Kimia. Ludo Kimia adalah permainan ludo yang telah dimodifikasi sedemikian rupa yang berisikan soal-soal latihan yang bertujuan untuk memantapkan konsep siswa mengenai materi bentuk molekul. Permainan Ludo Kimia dapat menarik minat siswa, 
karena dalam permainan ini seluruh siswa terlibat aktif dalam proses pembelajaran. Pembelajaran cara ini lebih efektif karena menciptakan suasana belajar yang menyenangkan dan lebih santai bekerja dalam kelompok. Setelah pembelajaran siswa diberikan latihan yang berfungsi untuk memantapkan konsep siswa terhadap materi yang telah dipelajari sehingga diperoleh keterampilan baru [9].

Ludo Kimia ini dimodifikasi dengan menambahkan gambaran umum materi yang berhubungan dengan materi Bentuk Molekul, kemudian dilengkapi dengan soal latihan yang digunakan sebagai pengganti soal latihan yang biasanya diambil dari buku teks, modul, dan LKS. Pembelajaran dengan cara ini lebih efektif karena siswa merasa lebih santai bekerja dalam kelompok dan dapat meningkatkan jiwa kompetisi siswa. Salah satu manfaat belajar sambil bermain adalah menghilangkan stress dalam lingkungan belajar dan meningkatkan proses belajar [3].

\section{Metode}

Jenis penelitian yang digunakan adalah penelitian dan pengembangan atau Research and Development $(R \& D)$. Model pengembangan yang digunakan ini adalah model 4-D (four D models) yang terdiri atas 4 tahap, yaitu pendefinisian (define), perancangan (design), pengembangan (develop), dan penyebaran (disseminate) [4]. Penelitian ini dibatasi pada tahap develop (pengembangan) yaitu uji validitas dan praktikalitas terhadap produk yang dikembangkan. Penelitian ini bertujuan untuk menghasilkan sebuah produk berupa Ludo Kimia sebagai media pembelajaran alternatif yang valid dan praktis untuk digunakan dalam meningkatkan aktivitas belajar dalam mengerjakan latihan dan memantapkan konsep siswa. Penelitian ini dilaksanakan di FMIPA UNP dan SMAN 2 Pariaman pada tahun ajaran 2019/2020. Subjek penelitian ini adalah dua orang dosen jurusan kimia FMIPA UNP, dua orang guru kimia SMAN 2 Pariaman, dan 34 orang siswa XI IPA 2 SMAN 2 Pariaman.

Objek penelitian adalah Ludo Kimia sebagai media pembelajaran pada materi Bentuk Molekul kelas X SMA/MA. Instrumen penelitian yang digunakan pada penelitian ini berupa angket validitas dan praktikalitas. Angket ini digunakan untuk menentukan validitas dan praktikalitas dari Ludo Kimia sebagai pembelajaran pada materi Bentuk Molekul. Teknik analisis data yang digunakan adalah data deskriptif yang mendeskripsikan tingkat validitas dan praktikalitas media Ludo Kimia yang dikembangkan. Data yang diperoleh kemudian dianalisis menggunakan formula Kappa Cohen, dimana pada akhir pengolahan data akan diperoleh momen kappa. Momen kappa diperoleh dengan rumus berikut:

$$
\text { Momen kappa }(\kappa)=\frac{\rho_{o}-\rho_{\theta}}{1-\rho_{\theta}}
$$

Keterangan:

\begin{tabular}{c|c|c}
$\mathrm{K}$ & $=$ & Momen kappa \\
\hline$\rho_{\mathrm{O}}$ & $=$ & Proporsi yang terealisasi \\
\hline$\rho_{e}$ & $=$ & Proporsi yang tidak terealisasi
\end{tabular}
Tabel 1 .

Nilai momen kappa (k) berkisar dari 0 sampai 1. Interpretasi nilai momen kappa disajikan pada

Tabel 1. Interpretasi nilai Momen Kappa

\begin{tabular}{c|c} 
Interval & Kategori \\
\hline$\leq 0,00$ & Tidak \\
\hline $0,01-0,20$ & Sangat rendah \\
\hline $0,21-0,40$ & Rendah \\
\hline $0,41-0,60$ & Sedang \\
\hline $0,61-0,80$ & Tinggi \\
\hline $0,81-1,00$ & Sangat tinggi
\end{tabular}

\section{Hasil dan Pembahasan}

\subsection{Tahap Pendefinisian (define)}


3.1.1. Analisis ujung depan. Analisis ujung depan dilakukan dengan cara mewawancarai guru kimia SMAN 1 Sawahlunto dan SMAN 2 Pariaman. Berdasarkan hasil wawancara tersebut, diperoleh informasi bahwa (1) guru telah menggunakan media seperti buku teks, modul, Lembar Kerja Siswa (LKS), powerpoint, dan gambar; (2) guru telah memberikan latihan dalam bentuk soal-soal dari bermacam sumber seperti buku teks, modul, LKS, namun tidak semua siswa aktif mengerjakannya; (3) guru tertarik menggunakan media pembelajaran dalam bentuk permainan; (4) menurut guru, penggunaan media permainan dapat meningkatkan jiwa kompetitif serta melibatkan siswa secara aktif dalam proses pembelajaran.

3.1.2. Analisis siswa. Berdasarkan hasil wawancara terhadap guru dan menyebarkan angket kepada siswa di SMAN 1 Sawahlunto dan SMAN 2 Pariaman, diperoleh informasi bahwa: (1) guru telah memberikan latihan dalam bentuk soal-soal latihan, namun tidak semua siswa aktif mengerjakannya; (2) menurut siswa, guru belum pernah memberikan latihan dalam bentuk permainan, sehingga siswa tertarik menggunakan media pembelajaran dalam bentuk permainan; (3) siswa belum pernah menggunakan media pembelajaran dalam bentuk Ludo Kimia, sehingga siswa setuju menggunakan media Ludo Kimia sebagai variasi bentuk latihan pada materi Bentuk Molekul.

3.1.3. Analisis tugas. Analisis tugas bertujuan untuk merinci isi materi ajar secara garis besar. Analisis tugas pada materi Bentuk Molekul kurikulum 2013 revisi 2018 adalah berupa analisis Kompetensi Inti (KI) dan Kompetensi Dasar (KD). Berdasarkan analisis KI dan KD, dijabarkan menjadi beberapa Indikator Pencapaian Kompetensi (IPK). Materi Bentuk Molekul, KD yang harus dipenuhi adalah 3.6 Menerapkan Teori Tolakan Pasangan Elektron Kulit Valensi (VSEPR) dan Teori Domain Elektron dalam menentukan bentul molekul. Kompetensi dasar tersebut dijabarkan menjadi IPK yaitu sebagai berikut 3.6.1 Memahami konsep Teori Tolakan Pasangan Elektron Kulit Valensi (VSEPR) dalam menentukan bentuk molekul; 3.6.2 Meramalkan bentuk molekul berdasarkan struktur lewis suatu senyawa; 3.6.3 Meramalkan bentuk molekul berdasarkan konfigurasi elektron atau nomor atom penyusun suatu molekul dan hubungannya dengan kepolaran suatu senyawa; 3.6.4 Meramalkan bentuk molekul berdasarkan teori VSEPR; 3.6.5 Menentukan jumlah Pasangan Elektron Bebas (PEB) dan Pasangan Elektron Ikatan (PEI); 3.6.6 Menentukan notasi VSEPR suatu molekul; 3.6.7 Menentukan bentuk molekul suatu ion poliatomik; 3.6.8 Menentukan bentuk molekul suatu senyawa netral.

3.1.4. Analisis konsep. Analisis konsep merupakan identifikasi, merinci, dan menyusun secara sistematis konsep-konsep utama pada materi bentuk molekul. Konsep-konsep utama yang saling berkaitan pada materi bentuk molekul digambarkan dalam peta konsep.

3.1.5. Analisis tujuan pembelajaran. Berdasarkan IPK yang telah didapatkan, dapat ditentukan tujuan pembelajaran. Adapun tujuan pembelajarannya adalah melalui Ludo Kimia diharapkan siswa dapat terlibat aktif dalam proses belajar mengajar berlangsung, memiliki sikap ingin tahu, teliti, dan jujur dalam melakukan pengamatan dan bertanggung jawab dalam menyampaikan pendapat, menjawab pertanyaan dan memberi saran serta kritik. Dalam hal ini siswa dituntut untuk dapat memahami konsep Teori Tolakan Pasangan Elektron Kulit Valensi (VSEPR) dalam menentukan bentuk molekul, serta dapat menentukan bentuk molekul berdasarkan struktur lewis, konfigurasi elektron, dan berdasarkan teori VSEPR.

\subsection{Tahap Perancangan (design)}

Tahap design bertujuan untuk merancang media pembelajaran kimia dalam bentuk Ludo Kimia pada materi Bentuk Molekul. Prototipe perangkat media yang dirancang adalah Ludo Kimia sebagai media pembelajaran pada materi Bentuk Molekul. Perangkat permainan ini dikumpulkan dalam sebuah kotak. Satu set permainan terdiri dari papan dan aturan permainan, kartu soal dan jawaban, gelas pengocok dadu, bidak dan dadu, serta form penilaian. Prototipe awal dari produk yang dikembangkan dapat dilihat pada Gambar 1 sampai 3. 


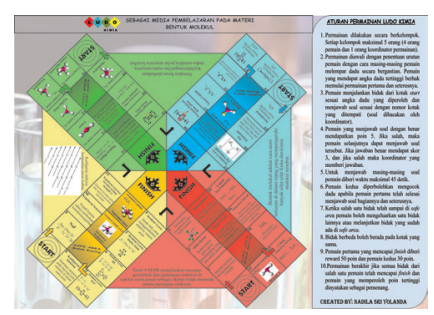

Gambar 1. Desain papan Ludo Kimia
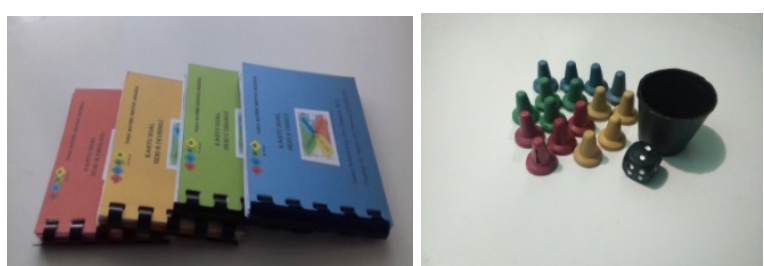

Gambar 2. Prototipe kumpulan kartu soal, dadu dan bidak
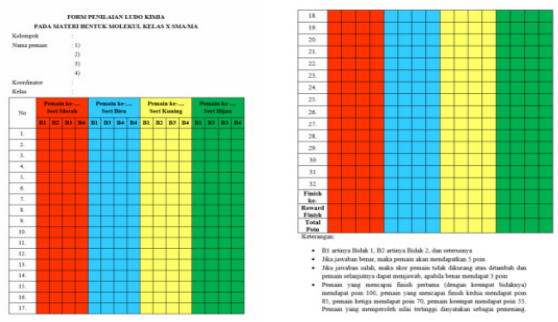

Gambar 3. Desain form penilaian pada Ludo Kimia

\subsection{Tahap Pengembangan (develop)}

Tahap ini bertujuan untuk menghasilkan media pembelajaran yang telah direvisi berdasarkan masukan dari berbagai pihak.

3.3.1. Uji Validitas. Uji validitas bertujuan untuk mengungkapkan validitas dari produk yang dikembangkan .Validasi produk dilakukan oleh dua orang dosen jurusan kimia FMIPA UNP serta dua orang guru kimia SMAN 2 Pariaman. Tingkat validitas produk ini didasarkan pada empat fungsi media, yaitu fungsi afektif, fungsi atensi, funsgi kognitif, dan fungsi kompensatoris. Hasil analisis nilai uji validitas dapat dilihat pada Gambar 4.

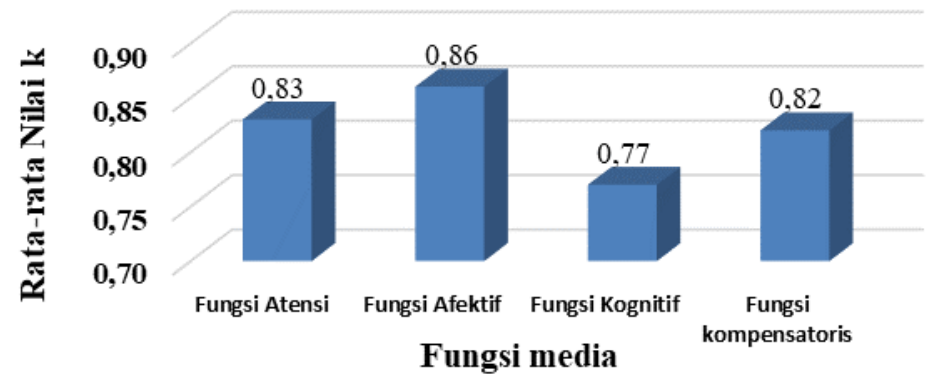

Gambar 4. Hasil analisis data validitas oleh validator

3.3.2. Uji Praktikalitas. Uji praktikalitas ini bertujuan untuk mengetahui tingkat kepraktisan media yang dikembangkan sebagai media pembelajaran kimia meliputi kemudahan penggunaan, dan efisiensi waktu pembelajaran. Penentuan tingkat praktikalitas produk dilakukan oleh dua orang guru kimia serta 34 orang siswa kelas XI IPA 2 SMAN 2 Pariaman. Uji ini dilakukan dengan cara menyebarkan angket 
praktikalitas. Hasil analisis nilai uji praktikalitas pada guru dan siswa dapat dilihat pada Gambar 5.

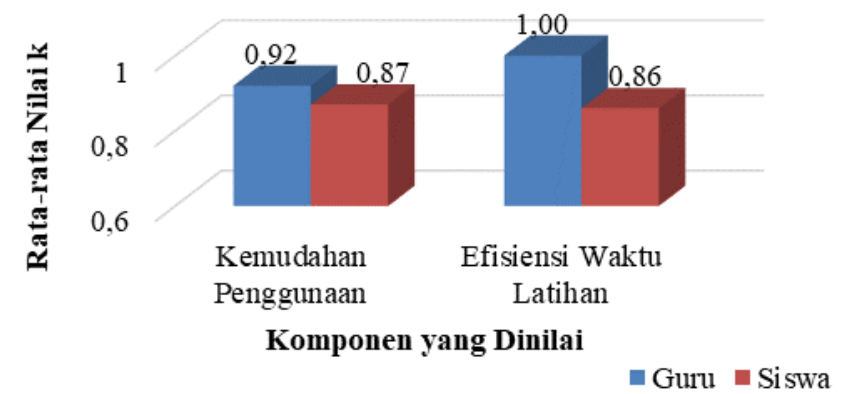

Gambar 5. Hasil uji praktikalitas oleh guru dan siswa

\subsection{Pembahasan}

\subsubsection{Penentuan Tingkat Validitas}

3.4.1.1. Fungsi atensi. Fungsi atensi media yaitu menarik dan mengarahkan perhatian siswa serta berkonsentrasi terhadap isi pembelajaran [5]. Berdasarkan analisis data penilaian dari validator terhadap fungsi atensi dari berupa Ludo Kimia sebagai media pembelajaran didapat nilai momen kappa sebesar 0,83 dengan tingkat validitas sangat tinggi. Hal ini menunjukan bahwa Ludo kimia sebagai media pembelajaran sudah mampu menarik dan mengarahkan perhatian siswa untuk berkonsentrasi pada isi materi.

3.4.1.2. Desain atau gambar yang berwarna dapat menarik perhatian siswa [6]. Minat dan perhatian siswa yang meningkat akan menyebabkan proses dan hasil belajar siswa akan semakin baik. Ludo Kimia yang dikembangkan telah memenuhi fungsi atensi dari suatu media sehingga dapat digunakan sebagai media pembelajaran pada materi Bentuk Molekul.

3.4.1.3. Fungsi afektif. Fungsi afektif media dapat membuat siswa tertarik sehingga motivasi belajar siswa meningkat dan mengunggah emosi serta sikap siswa [5]. Berdasarkan data penilaian dari validator terhadap fungsi afektif dari media pembelajaran berupa Ludo Kimia sebagai media pembelajaran didapat nilai momen kappa sebesar 0,86 dengan tingkat validitas sangat tinggi. Hal ini menunjukan bahwa media pembelajaran berupa Ludo Kimia sebagai media pembelajaran mampu menarik perhatian siswa untuk mengerjakan latihan, membuat siswa senang mengerjakan latihan dan membuat siswa aktif dalam mengerjakan latihan. Adanya permainan akan membuat siswa lebih berpartisipasi aktif dalam pembelajaran.

3.4.1.4. Fungsi kognitif. Fungsi kognitif yaitu media yang dapat memperlancar siswa mencapai tujuan pembelajaran serta memahami dan mengingat informasi yang terkandung dalam media tersebut [5]. Berdasarkan data penilaian dari validator terhadap fungsi kognitif dari media pembelajaran berupa Ludo Kimia sebagai media pembelajaran didapat nilai momen kappa sebesar 0,77 dengan tingkat validitas tinggi. Ludo Kimia yang dikembangkan dapat digunakan sebagai media pembelajaran pada materi Bentuk Molekul dengan tingkat validitas sangat tinggi karena telah memenuhi fungsi kognitif dari suatu media pembelajaran.

3.4.1.5. Fungsi Kompensatoris .Fungsi kompensatoris media adalah media dapat mengakomodasikan siswa yang lemah dan lambar dalam menerima dan memahami isi pelajaran [5]. Berdasarkan data penilaian dari validator terhadap fungsi kompensatoris dari media pembelajaran berupa Ludo Kimia sebagai media pembelajaran didapat nilai momen kappa sebesar 0,82 dengan tingkat validitas sangat tinggi. Hal ini menandakan bahwa soal-soal latihan yang terdapat dalam media pembelajaran berupa Ludo Kimia mampu membantu siswa yang lemah dalam menerima pelajaran menjadi mudah memahami dan memantapkan konsep terkait materi Bentuk Molekul. Melalui pemberian latihan akan dapat membantu 
siswa dalam memantapkan konsep terkait materi yang dipelajari [7]. Ludo Kimia yang dikembangkan telah memenuhi fungsi kompensatoris dari suatu media sehingga dapat digunakan sebagai media pembelajaran pada materi Bentuk Molekul.

\subsubsection{Penentuan tingkat praktikalitas}

3.4.2.1. Kemudahan penggunaan. Ludo Kimia pada materi Bentuk Molekul memiliki bahasa yang mudah dimengerti, petunjuk penggunaan yang mudah dipahami, mempermudah siswa memantapkan konsep, mudah dibawa, dapat dimainkan berulang kali, dan pemeliharaan relatif murah. Petunjuk pengajaran dapat diselenggarakan lebih efisien. Ludo Kimia memberikan interaksi antara guru dengan siswa, siswa dengan guru, dan siswa dengan siswa dapat dilihat pada Gambar 14. Berdasarkan data penilaian pratikalitas terhadap Ludo Kimia didapat nilai momen kappa praktikalitas guru dan siswa sebesar 0,92 dan 0,87 . Hal ini menunjukan bahwa media yang dikembangkan telah memenuhi satu ciri media yang praktis, yaitu kemudahan. Permainan dapat meningkatkan motivasi siswa dan mendorong siswa saling membantu satu dengan yang lainnya sehingga adanya interaksi [8].

3.4.2.2. Efisiensi waktu latihan. Praktikalitas Ludo Kimia sebagai media pembelajaran pada materi Bentuk Molekul tentang efisiensi waktu latihan didapat nilai momen kappa praktikalitas guru dan siswa sebesar 1,00 dan 0,86. Ludo Kimia pada materi Bentuk Molekul dapat dimainkan dimana saja dan kapan saja. Berdasarkan nilai momen kappa tersebut, menunjukan bahwa media yang dikembangkan telah memenuhi satu ciri media yang praktis.

\section{Simpulan}

Berdasarkan penelitian yang telah dilakukan, dapat diperoleh beberapa kesimpulan, yaitu Ludo Kimia sebagai media pembelajaran pada materi Bentuk Molekul kelas X SMA/MA: (1) dapat dikembangkan dengan model 4-D; (2) memiliki tingkat validitas dan praktikalitas yang sangat tinggi berdasarkan fungsi media dan ciri media praktis

\section{Referensi}

[1] UNESCO. 1988. Games Toys in The Teaching of Science and Technology. Paris. Division of Science Technical and Enviromental Educations.

[2] Tiarto, E.H., Suyatna, Agus., dan Sesunan, Feriansyah. 2013. Pengembangan Permainan Edukatif Materi Hukum Gravitasi Newton. Lampung: Universitas Lampung.

[3] Yusuf, Yasin dan Auliya, Umi. 2011. Sirkuit Pintar: Melejitkan Kemampuan Matematika \& Bahasa Inggris dengan Metode Ular Tangga. Jakarta: Visimedia.

[4] Trianto. 2012. Model Pembelajaran Terpadu. Jakarta: Bumi Aksara.

[5] Arsyad, Azhar. 2013. Media Pembelajaran. Jakarta: PT. Raja Grafindo Persada.

[6] Sudjana, N dan Rivai, A. 2011. Media Pengajaran. Bandung: Sinar Baru Algesindo.

[7] Hamalik, Oemar. 2008. Kurikulum dan Pembelajaran. Jakarta: Bumi Aksara.

[8] Latuheru, John. 1988. Media Pembelajaran dalam Proses Belajar-Mengajar Masa Kini. Jakarta: Departemen Pendidikan dan Kebudayaan.

[9] Alwarizna, S., Saadi, P., dan Rusmansyah. 2014. Meningkatkan Aktivitas dan Hasil Belajar Siswa dengan Metode Latihan Berstruktur dalam Materi Larutan Penyangga Siswa kelas XI IPA 1 SMA Negeri 6 Banjarmasin. Jurnal Inovasi Pendidikan Sains. Vol 5(2) 55-61. 